\title{
Quantitative analysis of crystal-interface frequencies in granitoids: Implications for modelling of parent-rock texture and its influence on the properties of plutoniclastic sands
}

\author{
Gert Jan Weltje ${ }^{\mathrm{a}, *}$, Bram Paredis $^{\mathrm{a}}$, Luca Caracciolo ${ }^{\mathrm{b}}$, William A. Heins ${ }^{\mathrm{c}}$ \\ ${ }^{a}$ KU Leuven, Department of Earth and Environmental Sciences, Celestijnenlaan 200E, 3001 Heverlee, Belgium \\ ${ }^{\mathrm{b}}$ FAU Erlangen-Nürnberg, Lehrstul für Geologie, Geozentrum Nord Bayern, Schlossgarten 5, 91054 Erlangen, Germany \\ c ExxonMobil Upstream Research Corporation, EMHC/S1.2A.531, 22777 Springwoods Village Parkway, Spring, TX 77389, USA
}

\section{A R T I C L E I N F O}

\section{Article history:}

Received 27 June 2017

Received in revised form 22 January 2018

Accepted 23 January 2018

Available online $\mathrm{xxxx}$

\section{Keywords:}

Crystal interfaces

Granitoids

Quantitative texture classification

Sediment generation

Compositional data analysis

\begin{abstract}
A B S T R A C T
Generation of sediments from crystalline rocks is the result of a complex and incompletely understood suite of processes. The time evolution of the rock-fragment assemblage in sands derived from granitoids is determined by the relative strengths of crystal interfaces and their abundances in the parent rock. In this study we highlight the role of crystal-interface frequencies in granitoids. Strong evidence for non-random texture with significant implications for predicted interface frequencies have been reported in previous studies. We analysed available interface-frequency data from granitoids using methods of compositional data analysis, and connected our results to existing texture classifications. On average, granitoids display a high degree of ordering with significant depletion of isomineralic interfaces relative to expectations based on random texture. Analysis of 210 normalized interface frequency distributions from nine different granitoids reveals a consistent pattern of variation among interface frequencies, which suggests a single underlying petrogenetic process related to the combined effects of nucleation and textural equilibration ("coarsening”).

In view of the large scatter of relative interface frequencies within and among granitoids, we propose to model their distribution empirically for the purpose of calibrating sediment-generation studies. Multivariate normal distributions of centred log-ratio transformed relative frequencies are capable of capturing $~ 95 \%$ of the observed variability with a limited number of dimensions. As a rule of thumb, the number of dimensions needed to approximate interface-frequency counts can be taken equal to the number of mineral classes, which is (much) smaller than the number of interface classes. Mathematical analysis shows that the joint variability of rock texture and composition may be factorized into three statistically independent measures: modal composition, crystal-size probability density functions, and normalized interface frequencies. The potential independence of these measures permits objective identification of petrogenetically significant correlations among them, which will be indicated by statistically significant cross-covariances. At this stage, inferences from microscopic texture analysis cannot be extrapolated to the scale of entire drainage basins in which sediments are generated, because insufficient data are available on the large-scale spatial heterogeneity of texture and composition of granitoid parent rocks.
\end{abstract}

(c) 2018 Published by Elsevier B.V.
"Ultimately, it seems evident that, since most geological populations possess interdependent interacting properties, the solutions to problems of geological interest will require multivariate statistical analysis." (Griffiths, 1961).

\section{Introduction}

Generation of sediment from crystalline parent rocks results from a combination of chemical and mechanical weathering. Studies covering the broad field of sediment generation have been mainly focused on

\footnotetext{
* Corresponding author.

E-mail address: gertjan.weltje@kuleuven.be (G.J. Weltje).
}

the role of chemical weathering in soil formation. The role of mechanical weathering, which is a first-order control on the relation between grain size and petrographic composition of sediments entering the fluvial transport system, has received much less attention and is still poorly understood (Heins, 1993, 1995; Heins and Kairo, 2007; Caracciolo et al., 2012; Weltje, 2012). Petrographic classification schemes of sands are grain-based and include several categories of rock fragments. Rock fragments are defined as grains which are polycrystalline and often also polymineralic. The size-composition evolution of the rockfragment assemblage of plutoniclastic sands has been analysed in terms of the relative strength of crystal interfaces (Heins, 1992, 1995; Caracciolo et al., 2012). The probability that interfaces are destroyed during mechanical weathering is inversely proportional to their 
strength, which implies that the strongest interfaces will become enriched in the rock-fragment assemblage as a result of progressive breakage. Conversely, the population of monocrystalline grains will become enriched in crystals whose interfaces are weakest on average. The elimination of relatively weak interfaces by breakage implies that rock fragments generated from crystalline parent rocks are expected to display a compositional trend of stronger interfaces with decreasing grain size, owing to the fact that rock fragments generated by breakage will be smaller (and more stable) than the parent rock fragment (Heins, 1995).

Another major control on the time evolution of the rock-fragment assemblage is the relative abundance of the different types of crystal interfaces in the parent rock, which defines the initial conditions for sediment generation (Heins, 1995; Caracciolo et al., 2012). Our approach to modelling of the time evolution of rock-fragment assemblages is based on the fact that these are compositional data, which should be statistically evaluated in the form of log-ratios (Aitchison, 1986). Research has shown that chemical and mechanical weathering trends (Von Eynatten et al., 2003; Von Eynatten, 2004; Weltje, 2012) can be successfully described by linear functions in the centred log-ratio space. Analogously, if mineral interfaces would possess characteristic relative strengths, the evolution of the composition of rock-fragment assemblages shed by different types of granitoid parent rocks should follow parallel trajectories in the centred log-ratio space, and the spread among these trajectories should reflect differences among initial conditions (i.e. parent-rock texture and composition), which define the starting point of each trajectory. Hence, if the effect of variable parent-rock texture and composition can be eliminated from interface data, all trajectories should collapse into a single one, from which relative interface strengths could be reliably estimated.

To accomplish this goal, we need a quantitative model of parentrock texture, which should at least specify the relations among modal composition and the joint distributions of interface frequencies and crystal size/shape in crystalline rocks (cf. Harvey and Ferguson, 1978) to provide an adequate description of the initial conditions for sediment generation. In this contribution, we provide a statistically compact description of frequency distributions of crystal interfaces in granitoid rocks through re-analysis of legacy data, and we propose guidelines for developing a generic quantitative description of crystalline texture aimed at constraining the initial conditions for sediment generation from granitoid parent rocks, and for testing of petrogenetic hypotheses, based on the formal scheme set out by Griffiths (1961).

\section{Size-composition evolution of rock-fragment assemblages}

The effects of mechanical weathering on the size-composition evolution of the rock-fragment assemblage may be described in terms of intra- and inter-crystal breakage (Weltje, 2012). Intra-crystal breakage, i.e. fragmentation of individual crystals, is most likely related to the crystallographic properties of minerals. For quartz grains, substantial evidence exists for the presence of microfractures, owing to the presence of dislocations and inclusions, as well as the direct result of the transition from high- to low-quartz during cooling and unloading (Moss, 1966; Smalley, 1966; Blatt, 1967; Moss and Green, 1975; Vollbrecht et al., 1991). Inter-crystal breakage, i.e. fragmentation of rocks along crystal interfaces, is not particularly well understood. The strength of crystal interfaces is inversely proportional to crystal size (Erkan, 1970; Simmons and Richter, 1976), because anisotropy of crystallographic properties creates interface strain owing to unloading, deformation, and temperature variations. In addition, straight crystal interfaces are weaker than more convoluted crystal interfaces which form a tightly interlocked framework.

Interface strengths are expected to differ among isomineralic, nonisomineralic isostructural, and non-isostructural interfaces (Savanick and Johnson, 1974; Heins, 1992, 1995; Caracciolo et al., 2012). The interface analysis of Caracciolo et al. (2012) indicates that in terms of stability, QQ $>$ PP $>$ QP $>$ PK (where Q P, and K stand for quartz, plagioclase, and K-feldspar, respectively). These are the interfaces with the highest mechanical preservation potential, consistent with the assessment of Heins (1995) regarding the higher preservation potential of non-isomineralic PK and QK interfaces compared to isomineralic KK bonds.

Deduction of interface properties from analysis of natural sediments is fraught with difficulties. In nature, mechanical weathering is enhanced by chemical weathering which acts as an important modifier of interface strength (McWilliams, 1966; Lidstrom, 1968; White, 1976; Pye, 1985, 1986). Moreover, analysis of interface frequencies in rock fragments can only tell us something about inter-crystal breakage. Possible clues to the relative importance of intra-crystal breakage and inter-crystal breakage in sediment generation are contained in discrepancies between the crystal-size distributions (CSDs) of minerals in parent rocks and their size distributions in derived sediments (Aleva, 1956a, 1956b, 1960; Moss, 1966; Smalley, 1966; Blatt, 1967; Hoskin and Sundeen, 1985; Moss and Green, 1975; Van Tassell and Grant, 1980).

\section{Models of interface-frequency distributions in crystalline rocks}

Quantitative characterization of the texture of granitoids requires information on the spatial distribution of crystals, which may be obtained through analysis of the locations of their centres or through interface counts. This information, which is complementary to the information obtained from analysis of CSDs, may provide valuable clues to petrogenesis (Ehrlich et al., 1972; Jerram et al., 2003). In the field of quantitative texture analysis, the focus lies mostly with analysis of CSDs of minerals (Marsh, 1988; Higgins, 2000, 2006). Evaluation of interface-frequency data for the purpose of quantitative textural analysis of igneous and metamorphic rocks has not been particularly widespread. A measure that is closely related to interface frequency and has been used more often, especially in engineering geology and geomechanics, is the specific surface area or interface density, expressed as interface area per unit volume (Erkan, 1970; Higgins, 2006).

Our choice to characterize texture by means of interface frequencies rather than interface surface area per unit volume is based on the fact that the former are unrelated to the CSD, unlike the latter. Conversion of interface frequencies to interface density (area per unit volume) is straightforward if information on the length of the traverses used during interface counting is available. Interface densities may be calculated according to the following formula (Erkan, 1970; Higgins, 2006):

$s_{i}=\frac{2 f_{i} d}{a_{0}}=\frac{2 f_{i}}{L}$

where $i$ represents an interface between two mineral phases within the rock, $s$ is the interface area per unit volume, $f$ is the number of interfaces, $d$ is the distance between traverses, $a_{0}$ is the area of the analysed surface, and $L$ is the total traverse length. The total number of interface classes $k=1 / 2 m(m+1)$, where $m$ equals the number of mineral phases in a rock. The total interface density, $S=\sum_{i=1}^{k} s_{i}$ is often related to mechanical rock properties (Erkan, 1970). An example of the conversion from interface frequencies to densities can be found in Heins (1995).

Caracciolo et al. (2012) provided the first integrated quantitative 2-D description of granitoid rock texture and composition, in which interface frequencies (and lengths), modal composition and CSDs were measured on the same set of samples. The results (summarized in their Fig. 2) show that all three distribution types vary simultaneously. It is intuitively obvious that the modal composition could vary independently from the CSD (at least if the number-frequency 
distribution of crystal types has been formulated as a probability density function), but relating the frequency distributions of interface types to any of these quantities is not exactly straightforward.

In a rock consisting of multiple minerals, the spatial distribution and abundance of crystals of each mineral in a given volume (or on a given area, or along a linear transect) may be characterized by counting the transitions of crystals of each mineral to those of each of the other minerals, to give an interface-frequency distribution. The number of crystals of each mineral encountered may be summarized in the form of a number-frequency distribution of crystals of each mineral. The relation between these two distributions provides information on the spatial arrangement of the crystals of each mineral in the rock under investigation.

A generic statistical description of interface-frequency distributions in granitoid rocks requires a suitable baseline or reference model, against which one may compare available data. A random spatial arrangement of crystals provides the simplest reference model of rock texture. Analogous to Jerram et al. (1996, 2003), we therefore propose a "normalized" interface-frequency model which is independent of the number-frequency and size distributions of crystals by evaluating the interface frequencies relative to a theoretical reference model of random texture. If the interface and number frequencies have been divided by their totals, they will be referred to as relative frequencies (proportions). Relative frequencies carry the same information as absolute frequencies if the absolute numbers merely reflect the sample size, and the data can be regarded as compositional, i.e., the only information contained in such data lies with (log)ratios of quantities. In rocks with random texture (consisting of at least two minerals, say $A$ and $B$ ), relative interface frequencies of crystals are uniquely related to the relative number frequencies of each mineral. Relative frequencies (proportions) may be viewed as probabilities of occurrence. Random texture implies that probabilities of transition from one mineral to another are independent events. It thus follows from elementary probability theory that random texture is characterized by the following relation:

$f_{A A}=n_{A}^{2}, \quad f_{B B}=n_{B}^{2}, \quad f_{A B}=2 n_{A} n_{B}$

where $f$ are the relative interface frequencies and $n$ are the relative number frequencies of minerals. This reference model depends only on the (relative) number-frequency distribution of minerals in the rock. It is independent of the CSDs of the minerals involved, because it is object-based: each crystal is equally important, irrespective of its size. Decoupling of interface-frequency data from the CSDs of minerals is essential for statistical analysis, because it permits the two sets of variables to be statistically independent. Given this possibility, any statistically significant correlation among the two sets of variables implies that the data reflect (non-random) petrogenetic processes.

Models specifically aimed at quantifying the spatial distribution of crystal centres in 2-D were developed and applied by Jerram et al. (1996, 2003). Their method is based on calculating the distance between the centre of a crystal and the centre of its nearest neighbour for all crystals in the area investigated, to produce a distribution of nearest-neighbour distances that characterizes the spatial crystal distribution. In order to facilitate interpretation, the mean nearest-neighbour distance is normalized to the value of the mean nearest-neighbour distance of a random distribution of points with the same population density. This approach should work well in cases of low volumetric abundances and small crystal sizes of minerals, because in such cases, the sum of the radii of the crystals may be ignored relative to the distance between their centres. By definition, the minimal distance between the centres of two crystals must be larger than the sum of their radii, which could introduce an unwanted dependency of spatial distribution on CSD in the case of large volumetric proportions of minerals that have comparatively large crystal sizes.

Jerram et al. (1996) distinguished three types of texture: ordered, random, and clustered (ORC). These concepts may be clarified by considering the simplest possible case of 1-D texture measurements, where a rock is represented by a string of beads of two types, $A$ and $B$ (Fig. 1). If the total number of beads is defined as $N$, and we assume that the string is made up of equal numbers of beads of type $A$ and $B$, the following limiting texture classes may be defined in terms of relative interface frequencies:

$\begin{array}{llll}\lim _{N \rightarrow \infty} \mathrm{O}: & f_{A A}=0 & f_{B B}=0 & f_{A B}=1 \\ \lim _{N \rightarrow \infty} \mathrm{R}: & f_{A A}=\frac{1}{4} & f_{B B}=\frac{1}{4} & f_{A B}=\frac{1}{2} \\ \lim _{N \rightarrow \infty} \mathrm{C}: & f_{A A}=\frac{1}{2} & f_{B B}=\frac{1}{2} & f_{A B}=0\end{array}$

Hence, $\mathrm{O}$ (rdered) refers to the case in which beads of type $A$ and $B$ alternate, and $C$ (lustered) refers to the case in which the first half of the string contains only beads of type $A$ and the second half of the string only beads of type $B$. R(andom) speaks for itself. It should be noted that in reality, none of the observed frequencies could ever be equal to zero, and we therefore propose the following operational definition of Ordered and Clustered texture for our hypothetical string of beads:
O : $f_{A A}=\delta \quad f_{B B}=\delta \quad f_{A B}=1-2 \delta$
C : $f_{A A}=\frac{1}{2}-\delta \quad f_{B B}=\frac{1}{2}-\delta \quad f_{A B}=2 \delta$

Replacement of zero values by a small positive number $\delta$ is justified in view of the finite sample size of actual data, and is required for employing the statistical techniques outlined in this paper.

\section{Petrogenetic considerations and previous work}

Strong evidence exists for non-random spatial distribution of minerals in granitoids (Flinn, 1969; Vistelius, 1972, 1987). The notion that granitoid texture is unlikely to be random follows logically from petrogenetic considerations. Ordered texture is induced by local melt depletion owing to crystallization of a mineral, which would decrease the probability that a crystal of the same mineral could grow in its immediate vicinity. The spatial distribution of nucleation sites of at least some minerals would thus tend to be uniform instead of random. Although the initial growth of crystals in magma is driven by kinetic forces, and the resulting textures can be preserved in rapidly cooled igneous rocks, crystals in such rocks have a high surface area with respect to their volume, and hence an excess surface energy. This energy can be dissipated by textural equilibration. At advanced stages, this is represented by textural coarsening, in which smaller crystals dissolve

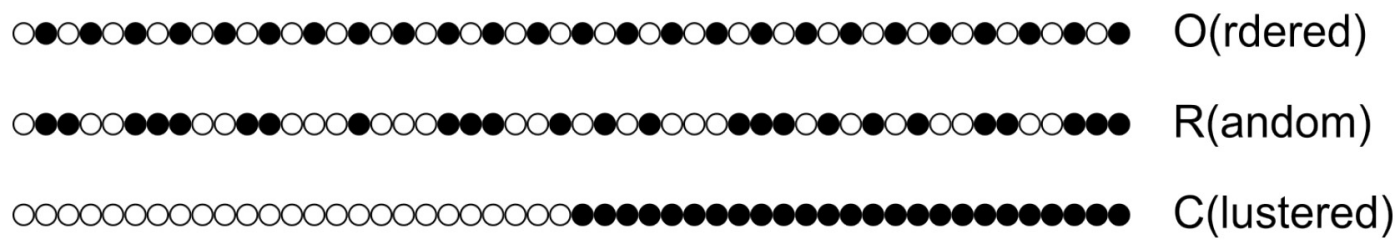

Fig. 1. Ordered, random and clustered texture represented in one dimension by strings with identical numbers of black and white beads. 
simultaneously with the growth of larger crystals. These textural changes occur commonly in slowly cooled plutonic rocks and may be important for the development of some volcanic rocks as well (Higgins, 2011). Under the assumption that crystals do not move relative to each other during nucleation and growth, coarsening would also lead to a spatially uniform distribution of crystals of the same mineral, and fewer isomineralic interfaces than expected under conditions of spatially random crystal growth. Hence, both nucleation and textural coarsening would promote relative depletion of isomineralic contacts in igneous rocks.

Rogers and Bogy (1958) were the first to examine the spatial distribution of minerals by measuring crystal-interface lengths of quartz, plagioclase, K-feldspar, and mica from 31 granitoids. The same analysis was repeated by Mahan and Rogers (1968) for 18 different metamorphites. In both studies, it was concluded that isomineralic contacts are less abundant than expected under the assumption of random texture. Despite these encouraging results, the approach to quantification in these two studies leaves much to be desired, because contact lengths were "normalized" by dividing them by modal abundance of phases, which would have been correct only in the unlikely case that all minerals have the same crystal-size and -shape distributions. In subsequent studies of granitoids (Flinn, 1969) and a granulite (Kretz, 1969; Whitten et al., 1975) this error was corrected. In all of the above studies (with the exception of Kretz, 1969), it was concluded that on average, fewer isomineralic contacts were observed than expected under the assumption of randomness.

A comprehensive research programme aimed at analysing crystal interface frequencies in granitoids was initiated in the 1960s by Andrei Vistelius (Laboratory of Mathematical Geology, Leningrad, USSR). He developed a method of measuring interface frequencies of QPK crystals along parallel linear transects across specially prepared thin sections of $10 \times 10 \mathrm{~cm}$, and attempted to deduce petrogenetic information from statistical analysis of these QPK interface data. The theoretical foundation of this work rests on a model of ideal granite texture based on the theory of Tuttle and Bowen (1958), which was statistically implemented in the form of a Markov Chain (Vistelius, 1972). Successful application of the line-counting method in mineral prospection spurred further development of the model with the aim to describe different types of departures from an ideal granite texture, which need not concern us here, and for which the interested reader is referred to Vistelius (1987).
Most recent attempts to quantify igneous and metamorphic rock texture have been based on 2-D data obtained by digital image analysis (Morishita and Obata, 1995; Jerram et al., 1996, 2003; Higgins, 2006; Caracciolo et al., 2012). Contrary to most methods, which are object (i.e., crystal) based, the pixel-based approach of Morishita and Obata (1995) and Morishita (1998) may be regarded as an implementation of conventional two-point geostatistics, because use is made of the spatial autocovariance (semivariance) of pixels classified as belonging to specific minerals, which may be regarded as a form of Indicator Kriging (Isaaks and Srivastava, 1989). This method does not recognize individual objects, but provides a general view on the spatial continuity of pixels belonging to a particular mineral within a rock.

Jerram et al. (2003) concluded from analysis of the spatial distribution of crystal centres that clustered distributions of phenocrysts (glomerocrysts) are common in volcanic rocks and shallow-level intrusions. These crystal clusters may originate from various mechanisms, such as heterogeneous nucleation, remobilization of cumulate mushes, or crystals sticking together during settling and/or flow (Higgins, 2006). Thus, in contrast to ordered texture, which supposedly reflects "static" crystallization and textural coarsening, clustered texture reflects 'dynamic' conditions under which crystals are free to move relative to each other.

\section{Material}

Data of QPK (Quartz, Plagioclase, K-feldspar) interface frequencies from linear traverses across thin sections of granitoids were retrieved from four references: Vistelius and Harbaugh (1980), Vistelius et al. (1983), Sharp and Severance (1991), and Heins (1992). The method for obtaining the raw interface frequencies is illustrated in Fig. 2. Detailed accounts of the data-acquisition protocol may be found in Whitten and Dacey (1975), Vistelius and Harbaugh (1980), and Vistelius et al. (1983). A fifth source of similar data was Caracciolo et al. (2012) in which interface frequency data were obtained from thin sections by using a microscopic information system (MIS). An overview of the data base used in this study is shown in Table 1. For a detailed description of all data sets the reader is referred to the accompanying references.

Altogether, 210 QPK interface-frequency samples from 9 different plutons were analysed in this study (Online Supplement A). Most samples are granite or granodiorite with some occurrences of orthogneiss

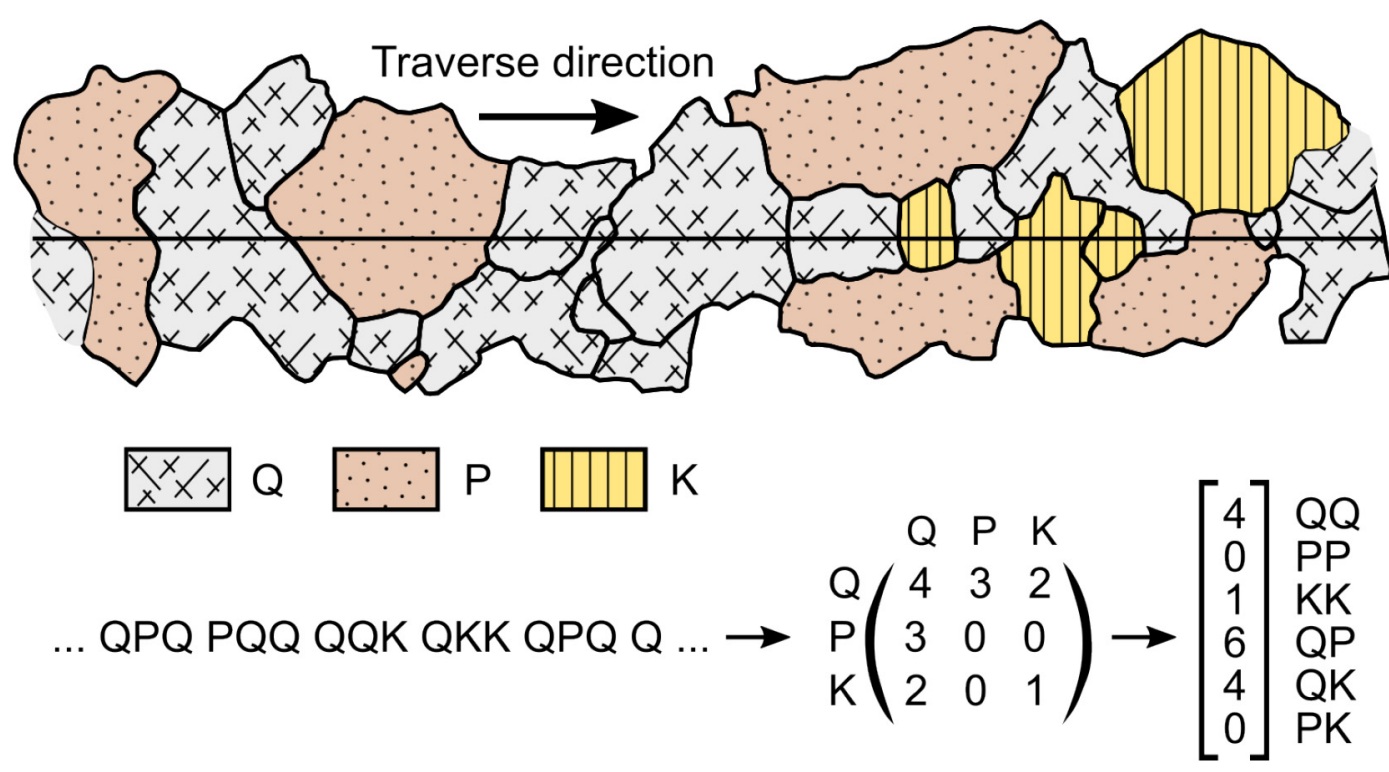

Fig. 2. Data-acquisition protocol: line counting and definition of interface frequencies (modified from Vistelius et al., 1983). 
Table 1

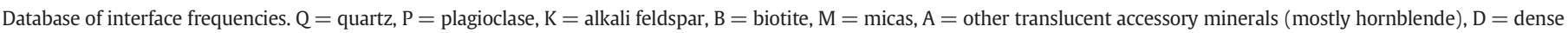
minerals; $\mathrm{O}=$ opaque minerals.

\begin{tabular}{|c|c|c|c|c|c|c|}
\hline Pluton & Locality & IUGS classification & Interfaces & No. samples & Reference & Code \\
\hline Yosemite Valley & USA (CA) & Granodiorite & QPK & 6 & Vistelius and Harbaugh (1980) & YV \\
\hline Meech Lake & Canada (QC) & Granite/(Orthogneiss) & QPK & 146 & Vistelius et al. (1983) & ML \\
\hline Pacolet Mills & USA (SC) & Monzogranite/orthogneiss & QPKB & 2 & Sharp and Severance (1991) & PM \\
\hline Granite Wash Mountains & USA (AZ) & Granodiorite & QPKBOA & 15 & Heins (1992) & $A Z$ \\
\hline Kinney Lakes Granodiorite & USA (CA) & Granodiorite & QPKBOA & 12 & Heins (1992) & $\mathrm{CA}$ \\
\hline McCartney Mountain Stock & USA (MT) & Granodiorite & QPKBOA & 9 & Heins (1992) & MT \\
\hline Mt. Stuart Batholith & USA (WA) & Granodiorite & QPKBOA & 4 & Heins (1992) & WA \\
\hline Ocotito Granitoid Complex & Mexico (GRO) & Granodiorite & QPKBOA & 11 & Heins (1992) & GR \\
\hline Aar Massif & Switzerland & Monzogranite/orthogneiss & QPKMD & 5 & Caracciolo et al. (2012) & $\mathrm{AA}$ \\
\hline
\end{tabular}

and monzogranite according to the IUGS classification (Le Bas and Streckeisen, 1991). The major part of the 146 samples of Vistelius et al. (1983) are classified as granite but are referred to as aplite because of the subhedral-anhedral fabric and sugary texture (small average crystal size). The data set of Heins (1992), consisting of 51 samples from 5 different granodiorites, displays a wide range of crystal sizes.

To account for the large differences in sample size at the level of individual plutons, the data set was split into two subsets: The Meech Lake pluton data of Vistelius et al. (1983) containing 146 samples, and the remaining set of data from 8 plutons to which we added 10 randomly selected samples from the data set of Vistelius et al. (1983), giving a total of 74 samples (Online supplement A). The first represents an in-depth study of a single pluton, and the second a (hopefully representative) overview of interface frequencies based on 9 different granitoids.

The full interface-frequency data set of Heins (1992) incorporates BOA (Biotite, Opaques, Accessories) interface frequency data in addition to the QPK data (Online supplement B). Accessories include (in decreasing volumetric order): hornblende, sericite/muscovite (usually as alteration product of $\mathrm{P}$ ), zircon, sphene, apatite (usually as inclusion in B or hornblende), epidote, calcite (usually as alteration product of $\mathrm{P}$ ), rutile (usually as inclusion in $\mathrm{Q}$ or B). Details on the dataacquisition protocol with discussion of the criteria for identifying isomineralic interfaces is included in Appendix 1. Interface data related to the opaque minerals were not used in the present analysis, because OO interfaces cannot be unambiguously defined with optical microscopy in translucent light. The remaining QPKBA interface data have been analysed with the same methods as the QPK data. Total traverse lengths $L$ are also included in Supplement B.

\section{Methods}

\subsection{Testing of randomness}

For the sake of simplicity, we consider a rock composed of QPK crystals only. The vector of observed interface frequencies is defined as $\mathbf{f}_{\mathrm{QPK}}=\left(f_{\mathrm{QQ}}, f_{P P}, f_{K K}, f_{\mathrm{QP}}, f_{\mathrm{QK}}, f_{P K}\right)$ and the total number of observed interfaces is defined as $F=\sum_{i=1}^{k} f_{i}$, where $k$ represents the number of interface classes. The vector of number frequencies is given by: $\mathbf{n}_{\mathrm{QPK}}=\left(n_{\mathrm{Q}}, n_{P}, n_{K}\right)$. For a rock composed of $m$ different minerals, the total number of crystals observed equals $N=\sum_{j=1}^{m} n_{j}$. The number frequencies of crystals may be derived from the interface frequencies as follows:

$$
\begin{aligned}
& n_{Q}=f_{Q Q}+\left(f_{Q P}+f_{Q K}\right) / 2 \\
& n_{P}=f_{P P}+\left(f_{Q P}+f_{P K}\right) / 2 \\
& n_{K}=f_{K K}+\left(f_{Q K}+f_{P K}\right) / 2
\end{aligned}
$$

Dividing the elements of the vector of observed interface frequencies or observed crystal frequencies by their corresponding totals, $F$ and $N$ respectively, turns absolute into relative frequencies which represent proportions and may be viewed as probabilities of occurrence. Predicted relative interface frequencies, $\hat{\mathbf{f}}_{\mathrm{QPK}}$, under the random texture model are derived from relative crystal frequencies:

$$
\begin{array}{lll}
\hat{f}_{Q Q}=n_{Q}^{2} & \hat{f}_{P P}=n_{P}^{2} & \hat{f}_{K K}=n_{K}^{2} \\
\hat{f}_{Q P}=2 n_{Q} n_{P} & \hat{f}_{Q K}=2 n_{Q} n_{K} & \hat{f}_{P K}=2 n_{P} n_{K}
\end{array}
$$

Predicted absolute frequencies are then obtained by multiplying these predicted frequencies by their total, $F$. Deviations from the random model may be detected by testing if the expected distribution of interface frequencies matches the one observed (Davis, 2002). The standard approach is the Chi-squared test, which takes the following form for the 6-part QPK interface-frequency vectors:

$\mathrm{PCS}=\sum_{i=1}^{k} \frac{\left(f_{i}-\hat{f}_{i}\right)^{2}}{\hat{f}_{i}}$

The test statistic, PCS (Pearson's Chi Squared) is distributed as Chi squared with 5 degrees of freedom (one degree of freedom is lost because the sum of observed and predicted interface frequencies equals $F$ ). Critical values of this statistic are 9.24, 11.07, and 15.09 , for significance levels of $0.10,0.05$, and 0.01 , respectively. Deviation from randomness is considered significant if PCS exceeds the critical value at the adopted significance level. Hence, this test may be used to subdivide observed interface frequency vectors into random and nonrandom types.

\subsection{Normalization of observed frequencies by expected frequencies}

Non-random interface frequency vectors may be subdivided into ordered and clustered types by taking into account that isomineralic interfaces are expected to be less common than expected under the random model in the case of ordered texture (the 'ideal granite' of Vistelius, 1972), and more common than expected under the random model in the case of clustered texture (Jerram et al., 2003), as illustrated in Fig. 1.

This hypothesis may be tested by defining $\alpha_{i}=\ln \left(f_{i} / \hat{f}_{i}\right)$, and examining if the average of $\alpha_{i}$ is less than zero for each of the isomineralic interfaces by means of a $t$-test (Davis, 2002).

The above transformation, which normalizes observed interface frequencies by expected frequencies under the model of random texture decouples the description of interface frequencies from the number-frequency distribution of crystals, and therefore by extension also from the modal composition (because it was already shown that interface frequencies are decoupled from the CSDs of minerals). It should be stressed that we do not imply that 'normalized' interfacefrequency distributions are by necessity independent of modal and/or 


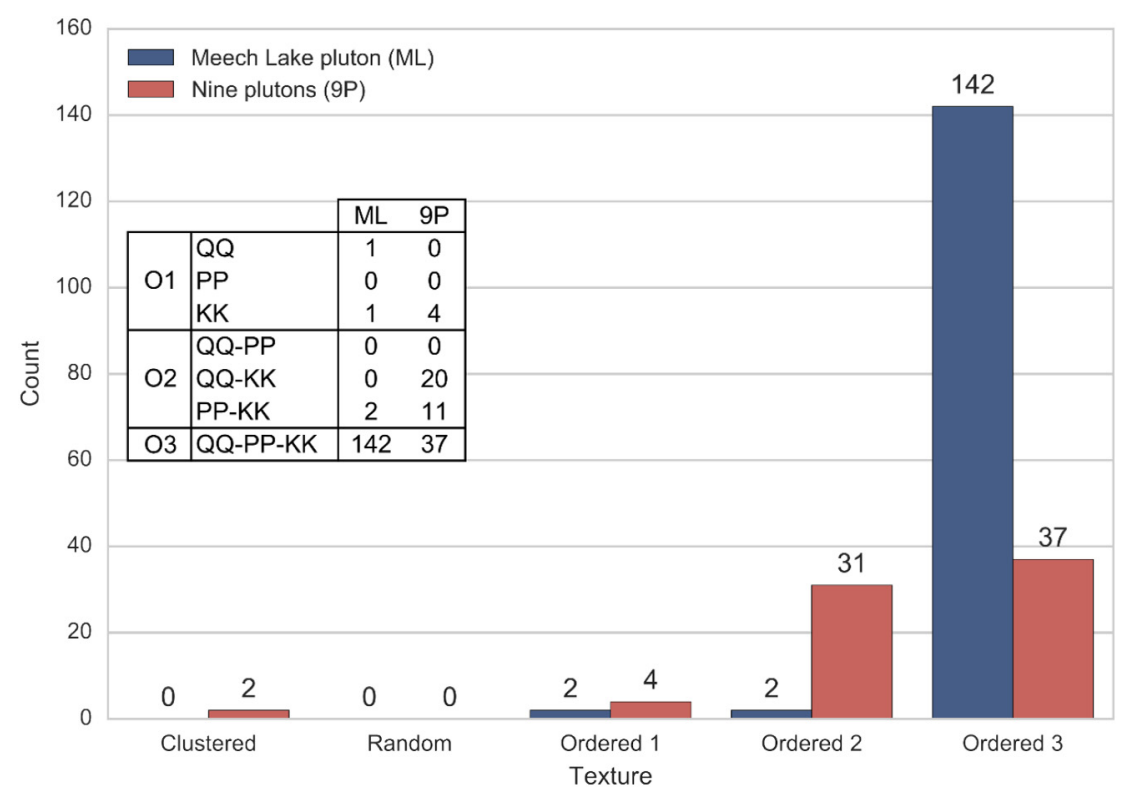

Fig. 3. Histograms of QPK texture classes in the two data sets. Inset gives overview of data in terms of degree of ordering (01-03).

number-frequency composition of granitoids, nor of the CSDs of their constituent minerals, but we prefer to decouple interface frequency data from these quantities in order to permit us to investigate if independence exists. From the point of view of exploratory data analysis and statistical model building, this approach could lead to a more parsimonious description of texture than the use of a compound property such as interface density, because interpretation of interface frequency data would be greatly facilitated if it can be shown that they are in fact independent of other textural and compositional properties.

Our implementation of the ORC system describes departure from randomness in much the same way as the system of Jerram et al.
(1996). But the two classifications are based on different types of data: relative interface frequencies versus relative mean nearest-neighbour distances of crystals. For texture to be (partially) ordered we merely require that one of the isomineralic $\alpha_{i}$ coefficients is negative, which implies that one or two minerals may actually have non-negative $\alpha_{i}$ coefficients. The 'ideal granites' of Vistelius (1972) for which all isomineralic $\alpha_{i}$ coefficients are negative are therefore a subset of the ordered texture types as defined in this paper. A potential refinement of the ORC system would be to distinguish "ideal" (fully ordered) from 'non-ideal' (partially ordered) textures, so as to enrich the classification of Jerram et al. (1996) with the concepts of Vistelius (1972).

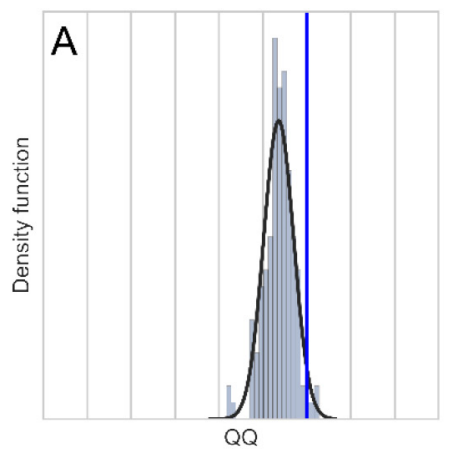

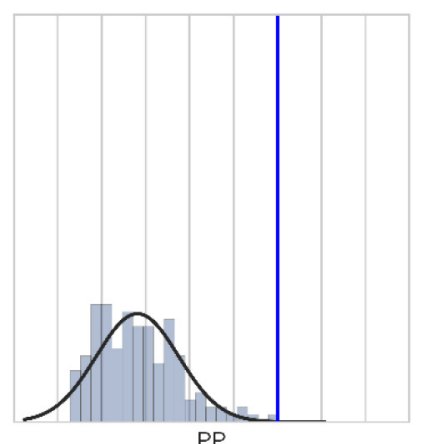

PP

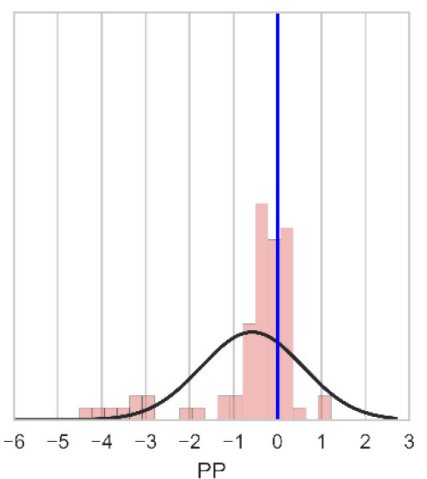

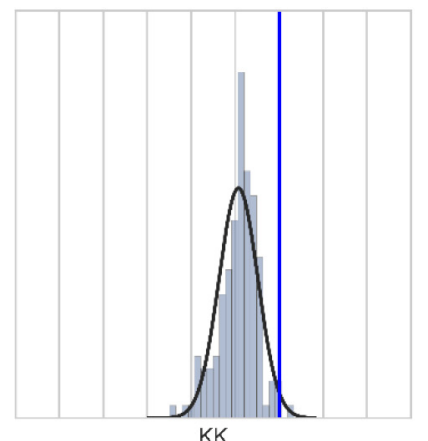

KK

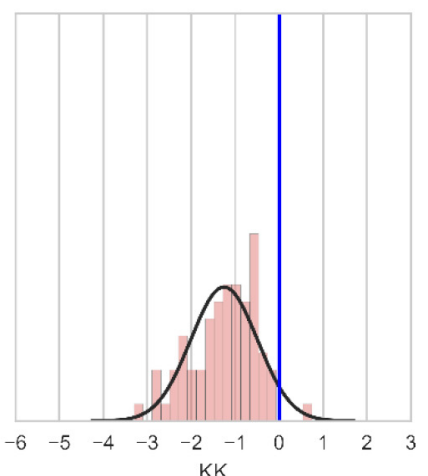

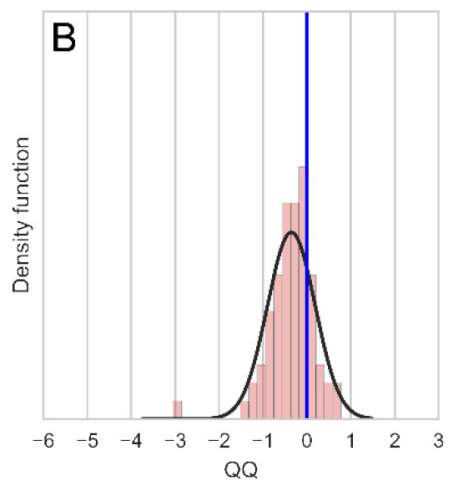

Fig. 4. Histograms of the normalized QPK interface frequencies of both data sets. 
Table 2

Results of t-test of normalized interfaces $\alpha$. Deviations from zero are statistically significant if the $p$ value is less than the significance level.

\begin{tabular}{|c|c|c|c|c|c|c|}
\hline & \multicolumn{2}{|c|}{ Meech Lake pluton } & \multicolumn{2}{|c|}{ Nine plutons } & \multicolumn{2}{|c|}{ Heins QPKBA } \\
\hline & $\mathrm{t}$ & $\mathrm{p}$ & $\mathrm{t}$ & $\mathrm{p}$ & $\mathrm{t}$ & $\mathrm{p}$ \\
\hline QQ & -22.72 & $1.3 \mathrm{E}-49$ & -5.57 & $4.0 \mathrm{E}-07$ & -4.64 & $2.5 \mathrm{E}-05$ \\
\hline $\mathrm{PP}$ & -40.91 & $1.6 \mathrm{E}-81$ & -4.26 & $6.0 \mathrm{E}-05$ & -0.69 & $4.9 \mathrm{E}-01$ \\
\hline KK & -25.16 & $9.2 \mathrm{E}-55$ & -14.10 & $1.6 \mathrm{E}-22$ & -11.98 & $2.6 \mathrm{E}-16$ \\
\hline BB & - & - & - & - & -16.05 & $2.3 \mathrm{E}-21$ \\
\hline $\mathrm{AA}$ & - & - & - & - & -2.84 & $6.5 \mathrm{E}-03$ \\
\hline t critical & -1.655 & & -1.666 & & -1.676 & \\
\hline DoF & 145 & & 73 & & 50 & \\
\hline alpha & 0.05 & & 0.05 & & 0.05 & \\
\hline
\end{tabular}

\subsection{Multivariate analysis of interface-frequency distributions}

More detailed insight into departures from randomness and correlations among interface types requires multivariate statistical analysis. Relative interface frequency data may be treated as compositions (Aitchison, 1986), which opens the way to more advanced multivariate methods of statistical analysis of interface-frequency data.

Subtracting the arithmetic mean of all log-ratios belonging to a single composition from the additive log-ratio values results in a centred log-ratio (clr) vector (Aitchison, 1986):

$\operatorname{clr}(\boldsymbol{\alpha})=\left(\alpha_{1}-\overline{\boldsymbol{\alpha}}, \ldots, \alpha_{i}-\overline{\boldsymbol{\alpha}}, \ldots, \alpha_{k}-\overline{\boldsymbol{\alpha}}\right)$

where $\overline{\boldsymbol{\alpha}}$ represents the arithmetic mean of the log-ratios: $\overline{\boldsymbol{\alpha}}=\frac{1}{k} \sum_{i=1}^{k} \alpha_{i}$.

Random texture coincides with the origin in clr-space. Hence, distance from the origin in clr-space is a natural measure of the degree of departure from randomness. The direction of departure describes the relative importance of ordering versus clustering.

A biplot of a series of clr vectors permits simultaneous evaluation of the samples and interface types in a space of reduced dimensions, similar to principal components analysis (Aitchison and Greenacre, 2002). In this type of plot, the Euclidian distances between data points are a direct measure of compositional dissimilarity. The direction of relative increase of each interface type within the data set is represented by an arrow originating at the grand mean of the data set. To facilitate interpretation in terms of texture, three artificial data points corresponding to ideal ordered $(-1,-1,-1,1,1,1)$, clustered $(1,1,1,-1$, $-1,-1)$, and random $(0,0,0,0,0,0)$ textures have been projected into the QPK interface biplots. The cumulative proportion of the variance which can be described by such models may exceed $95 \%$ with only a limited number of dimensions. The representation of clr-data in a reduced space provides an efficient way to summarize distributions of data points as multivariate normal (MVN) models with conventional statistics.

\section{Results}

The Chi-squared tests (online Supplement A) indicate that none of the interface-frequency distributions can be considered random. Out of 210 samples analysed, 208 display ordered texture and 2 display clustered texture (Fig. 3). Different degrees of ordering of granitoid textures (indicated by 01, 02, and 03) are observed. Highly ordered texture, in which isomineralic interfaces of $\mathrm{Q}, \mathrm{P}$, and $\mathrm{K}$ are all less abundant than expected under the assumption of random texture (03), is particularly common in granitoids. Also common are texture types in which two types of isomineralic contacts are less abundant than expected under the random model. The fine-crystalline Meech Lake pluton (Vistelius et al., 1983) displays a much higher degree of ordering than observed in the other (composite) data set. Histograms of the isomineralic $\alpha_{i}$ coefficients of the QPK interface data (Fig. 4 and Table 2) show that the average patterns conform to 'ideal' ordered textures, characterized by (highly) significant depletion of isomineralic interfaces. The most obvious difference between the two lies with the PP interfaces, which are extremely depleted in the Meech Lake pluton, and much less in the composite data set.

The biplot of the Meech Lake pluton (Fig. 5) shows that there is no difference between the textures of the stock and dikes. The biplot of the composite data set of nine plutons (Fig. 6) shows that relative interface data of individual plutons tend to cluster. However, the limited number of samples per pluton does not permit a rigorous assessment of these patterns. The variance in the clr-transformed QPK interface data can be effectively summarized in the reduced space of the biplots. Three dimensions permit description of $94.2 \%$ of the total variability in the Meech Lake pluton data, and $97.7 \%$ of the variability in the composite data of nine plutons. A closer look at the patterns within the interface data reveals a clear similarity in the arrangement of interface loadings (red arrows) of the two data sets. In both plots, PP and PK point in a direction opposite to QP and QK, whereas KK points in a different

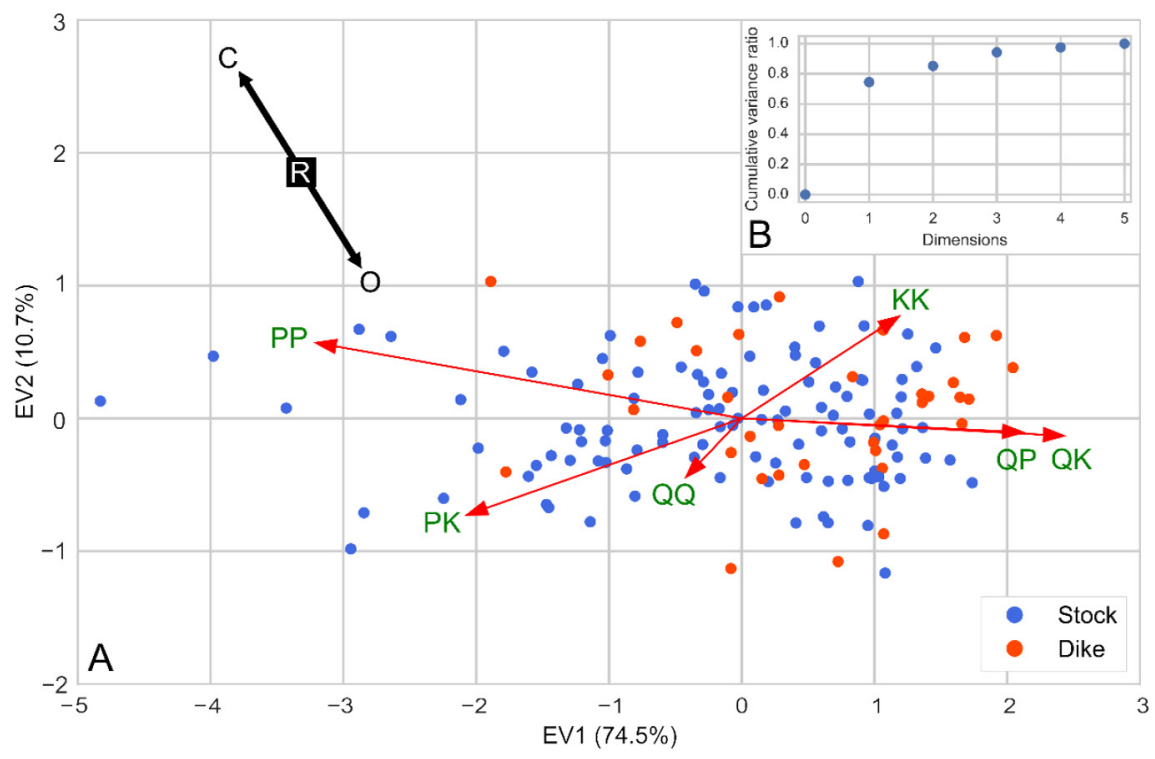

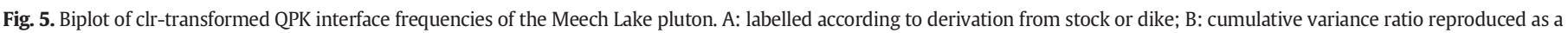
function of the number of dimensions in the model. 


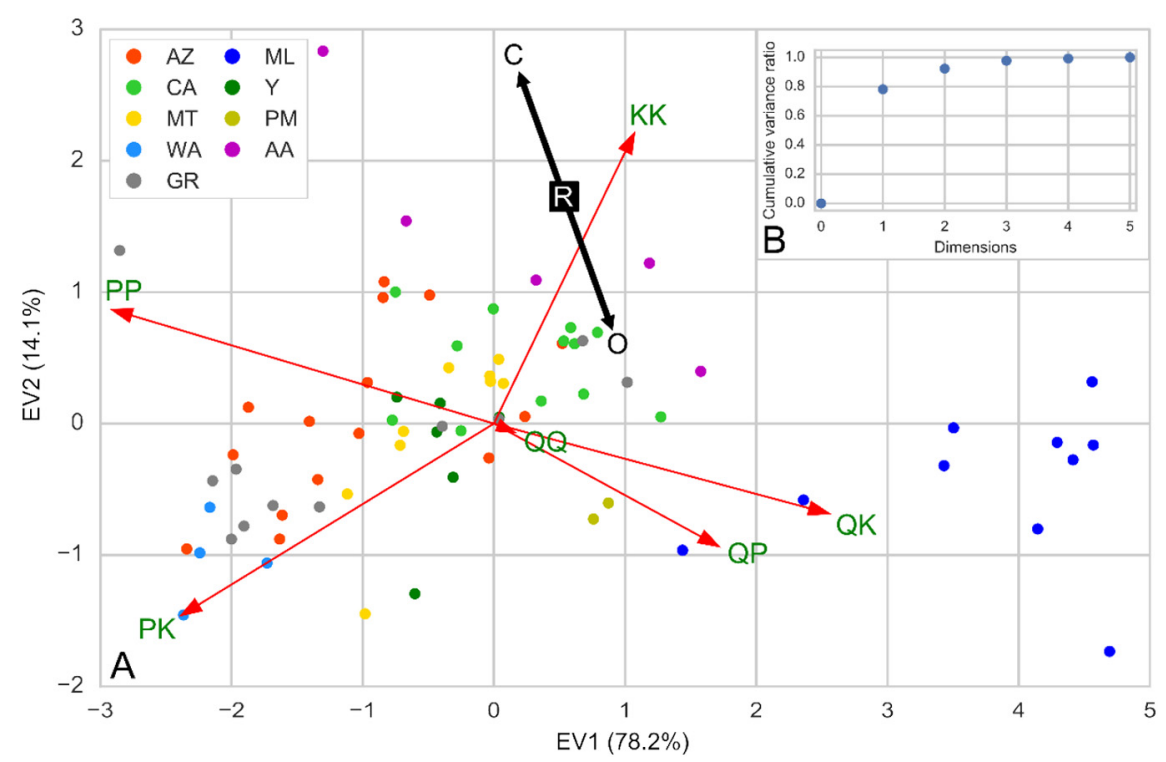

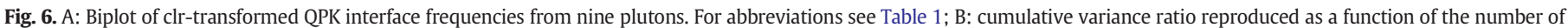
dimensions in the model.

direction, and QQ is remarkably small, indicating that its variability is not well correlated with that of the other interface types. The biplot of Fig. 6 illustrates that the Meech Lake pluton data form a separate cluster and thus are distinctly different from those of the other 8 granitoids analysed in this study.

Analysis of the full QPKBA data of the five plutons analysed by Heins (1992) is reported in Figs. 7 and 8, and Table 2. The univariate statistics (Fig. 7 and Table 2) show that all isomineralic interfaces are depleted relative to random texture, with the exception of $\mathrm{PP}$, whose relative abundances cannot be distinguished from those expected in the case of random texture (average $\alpha_{i}$ coefficient not significantly different from zero). The QPK interfaces in Fig. 8A shows again the same relationships as discussed above. Fig. $8 \mathrm{~B}$ and $\mathrm{C}$ illustrate that the BB interfaces behave differently from the other interfaces, and $A A$ tends to correlate with PP and PK. For the full QPKBA data set of Heins (1992), seven dimensions are needed to reproduce approximately $95 \%$ of the variance, as shown in Fig. 8D.

Fig. 9 provides a more detailed overview of the extent to which a reduced clr-space model is capable of capturing the patterns among interface frequencies observed in the three data sets analysed. It illustrates how much of the variance of clr-scores of individual interface types can be reproduced as a function of the dimensionality of the statistical model. The fact that data are not noise-free indicates that the maximum number of dimensions in the QPK interface data cannot exceed four (Fig. 9A, B). Similarly, the quality of approximation of the QPKBA data (Fig. 9C) does not seem to increase beyond seven dimensions. Analysis of all three data sets show that QQ interfaces are the most elusive, and cannot be captured by low-dimensional models (even though such models do describe the "behaviour" of all other interface types quite accurately).

\section{Discussion}

\subsection{Inferences from data analysis}

Our analysis of interface frequency distributions has demonstrated the advantages of a compositional approach over the traditional method of modelling such data as Markov Chains (Vistelius, 1972; Whitten and Dacey, 1975). The random texture model provides a convenient statistical device for 'normalizing' interface frequencies, even though the significance of random texture of crystalline rocks in the light of petrogenetic considerations remains unclear. Random texture could conceivably be inferred from interface counts averaged over multiple domains with ordered and clustered texture. It seems highly unlikely that this type of inhomogeneity can be observed at the scale of a thin section given the large crystal sizes of many minerals in granitoids. Hence, we suspect that the limited size of thin sections relative to crystal size does not permit recognition of random texture, which would also explain why it has not been encountered in the data. Random texture does have a clear meaning in the context of detrital sediments, as one of the distinguishing facts of detrital sediments is that grain 'interfaces' (contact points) are expected to be randomly distributed because the spatial distribution of grains is random.

Available interface-frequency data point to the overwhelming dominance of ordered texture in granitoid rocks, which is consistent with the concept of 'static' crystallization and textural coarsening during petrogenesis, and confirms inferences from previous studies (Rogers and Bogy, 1958; Flinn, 1969; Vistelius, 1972, 1987; Vistelius and Harbaugh, 1980; Vistelius et al., 1983). Interface-frequency patterns observed within a single pluton (Vistelius et al., 1983) are very similar to those averaged over multiple plutons (Figs. 3 and 4, and Table 2). The "behaviour" of QK and QP interfaces is opposite to that of PK and PP interfaces. KK interfaces tend to be different, but with slightly more affinity to QK and QP. We need three dimensions to capture their "behaviour" (Fig. 9A, B). QQ interfaces are not well represented in the plane of the first two eigenvectors shown in the QPK biplots (short vectors), because we need four dimensions to fully capture their "behaviour" (Fig. 9A, B), which appears to be largely independent of the relations among the other interface types. Because data are never noise-free, and the inclusion of higher dimensions will increase the risk of modelling the noise in the data instead of the signal, it seems likely that the actual number of dimensions needed to provide an adequate description of the normalized QPK interface-frequency patterns is equal to three. This implies that the pattern of QQ interfaces is more 'noisy' than that of the other interfaces. If we set the number of dimensions in the model equal to the number of mineral classes, and apply this empirical rule to the QPKBA data of Heins (1992), we arrive at the same conclusion with respect to the QQ interfaces. Again, the patterns displayed by all other interface types can be (fairly) well reproduced with this rule.

The extent of ordering tends to be different for Q P, and K among the nine plutons analysed in this study, with $\mathrm{P}$ showing the largest 

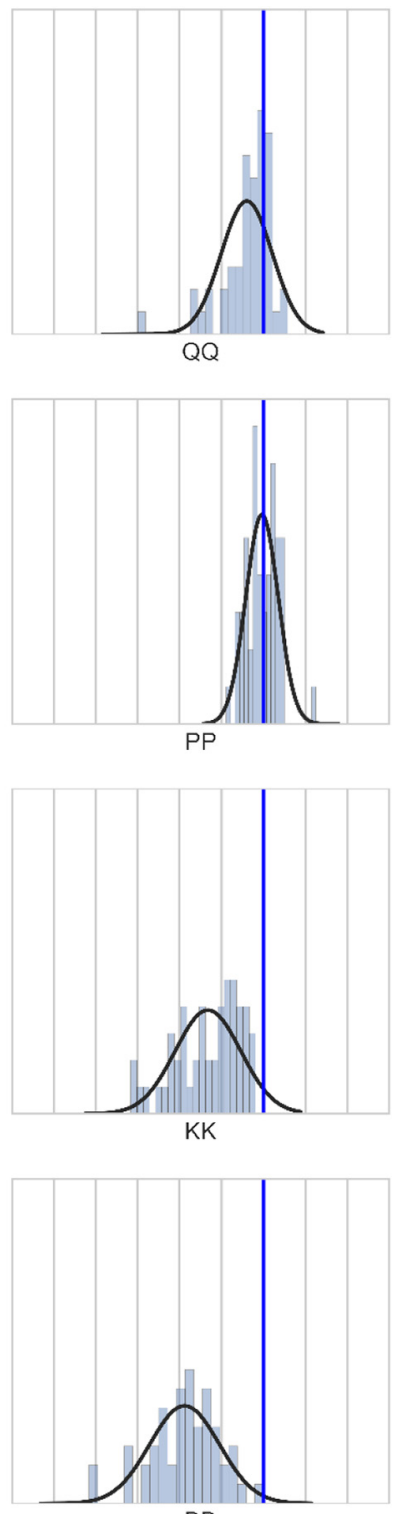

BB

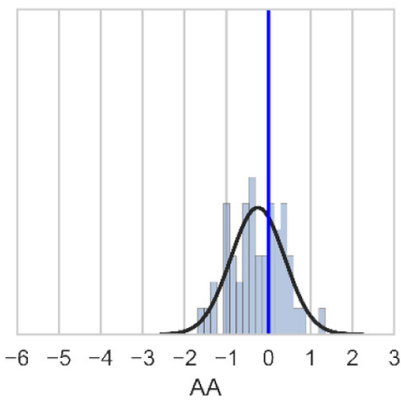

Fig. 7. Histograms of normalized QPKBA interface frequencies (Heins, 1992).

variability in the degree of ordering, ranging from perfectly ordered in the Meech Lake pluton to random in the five plutons analysed by Heins (1992). Between the data sets of Vistelius et al. (1983) and Heins (1992), which have been acquired with internally consistent (but not necessarily identical) data-acquisition criteria, lies a large difference in the perceived extent of ordering for all minerals. This may be in part due to systematic differences in operational definition of what constitutes an interface (see Appendix 1 for an in-depth discussion of criteria used by Heins, 1992). The fairly generous definitions of isomineralic interfaces by Heins (1992), coupled with the fact that such interfaces are more difficult to distinguish with decreasing average crystal size could offer an alternative explanation for the differences in degree of ordering reported among the data sets in Table 2. But even if the variation between these two data sets would be entirely attributable to operator error, this does not invalidate our conclusions based on the biplot analysis, because the "behaviour" of interface types relative to each other will not be affected by such systematic differences. In the clr-space, systematic error would merely shift the location of one data set relative to the other, but the relations among the clr-scores within each data set would be preserved.

In Fig. 10, the systematic differences between the Meech Lake data and those of the other eight plutons have been eliminated for the sake of improving our estimate of the covariance structure of the QPK interface data, by shifting the former in clr-space so that its average coincides with that of the other 8 plutons, which seem to represent a more common degree of ordering in granitoids. The biplot of all QPK interface data (Fig. 10A) illustrates that both data sets have essentially the same variance-covariance matrix, because the spread of the Meech Lake data points does not differ from that of the other 8 plutons. Hence, we conclude that the remarkable consistency of relative QPK interface patterns in the plutons investigated is likely to reflect an underlying mechanism related to the combined effects of nucleation and textural coarsening controlling the spatial arrangement of crystals. Similar to the conclusions reached on the basis of separate analyses of the two QPK data sets discussed above, the number of dimensions needed to describe the overall pattern of normalized QPK interface frequencies seems to be equal to the number of mineral classes (Fig. 10C), which permits reproduction of $\sim 95 \%$ of the variance of the entire data set (Fig. 10B), but does not capture the 'behaviour' of QQ interfaces.

The clr transformation evens out the contributions of each log-ratio to the total variance, which implies that comparatively rare interface types (corresponding to minerals which make a small contribution to the modal composition) carry the same weight as the dominant interface types. For the purpose of sediment-generation modelling, which is primarily concerned with bulk sediment properties, amalgamation of comparatively rare minerals into a single class is a practical measure to ensure that inferences remain robust in the light of sedimentgeneration studies if the number of minerals in a parent rock is large. If the number of minerals is equal to $m$, the total number of interface classes equals $1 / 2 m(m+1)$, which shows that the number of nonisomineralic classes increases rapidly with $m$.

Our overarching conclusion is that relative interface-frequency distributions of granitoids can be empirically modelled as multivariate normal (MVN) distributions in a reduced clr-space. The MVN model provides a compact description of the patterns observed in such data. Our analysis shows that we can accurately reproduce interfacefrequency data by choosing an MVN model whose rank equals the number of mineral classes (after optional amalgamation of rare minerals). At this stage we can only recommend the empirical approach to predicting interface-frequency distributions in granitoids with the MVN model, as we lack theory for interpreting the observed interfacefrequency patterns in a petrogenetically rigorous way. For the purpose of conducting future sediment-generation studies, we should therefore aim at analysing as many samples as possible in view of our limited insight into the natural scale of compositional and textural variability of granitoid parent rocks.

\subsection{Testing of petrogenetic hypotheses and simulation of granitoids}

A generic petrographic description of granitoid rocks should be aimed at characterising the (non-random) spatial distribution of crystals of multiple minerals that form a rock. In addition, each mineral should be allowed to have a different probability distribution of crystal sizes, and the extent to which minerals are likely to form interfaces may be placed in the spectrum from ordered to clustered texture. The 

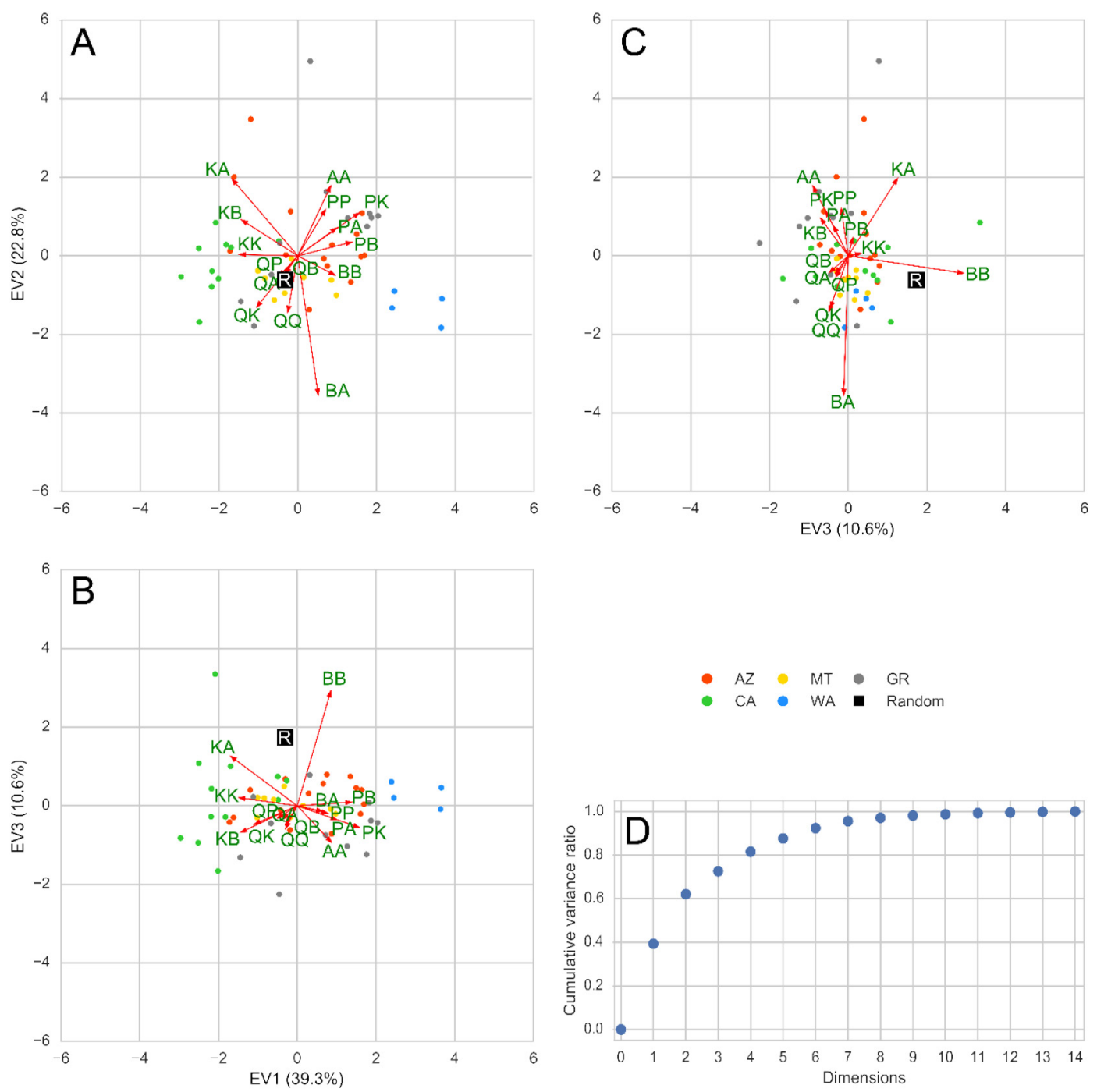

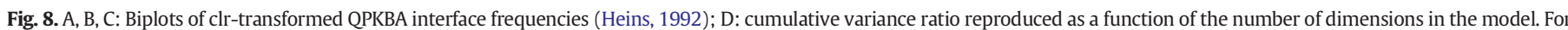
abbreviations of plutons see Table 1 .

spatial variability of modal composition of the rock is superimposed upon these patterns.

Our approach to normalization of interface frequencies to random texture ensures that interface-frequency models are independent of (relative) number frequencies of crystals, and therefore by extension, of modal composition. This is crucial for obtaining a parsimonious description of crystalline rock texture in which relative interface frequencies can be considered as an attribute of the rock which is in principle independent of the crystal-size and shape distributions of the minerals, as well as of their modal abundances.

The conventional approach to quantifying the distribution of crystal sizes of minerals in rocks is based on the CSD, which is defined as (Higgins, 2000, 2006):

$n_{j}=\int_{0}^{\infty} \tilde{n}_{j}(D) \partial D$

where $n_{j}$ is the total number of crystals of the $j$-th mineral per unit volume of rock, and $\tilde{n}_{j}$ is the number of crystals of the $j$-th mineral with crystal diameter $D$ per unit volume of rock. The CSD is intrinsically dependent on the modal composition of rocks, because it is based on the number frequency of crystals per unit volume per size range. This intrinsic dependency implies non-zero covariance among the parameters of CSDs, a phenomenon referred to as closure (Higgins, 2002).

The CSD may be decoupled from the modal composition by defining the cumulative size distribution of crystals as a probability density function (PDF):

$$
\int_{0}^{\infty} g_{j}(D) \partial D=1 \text {, which implies that } n_{j} \int_{0}^{\infty} g_{j}(D) \partial D=\int_{0}^{\infty} \tilde{n}_{j}(D) \partial D \text {. }
$$

The function $g(D)$ is the PDF of crystal size of the $j$-th mineral in the rock under investigation. It is independent of the number of crystals per unit volume. The average volume of crystals of a given mineral in the rock is defined as:

$\bar{v}_{j}=\sigma_{j} \int_{0}^{\infty} g_{j}(D) D^{3} \partial D$

where $\sigma$ is a crystal-shape factor (Higgins, 2000, 2006). In any fixed volume of rock $(V)$, the following must hold:

$x_{j} V=n_{j} \bar{v}_{j}$ 

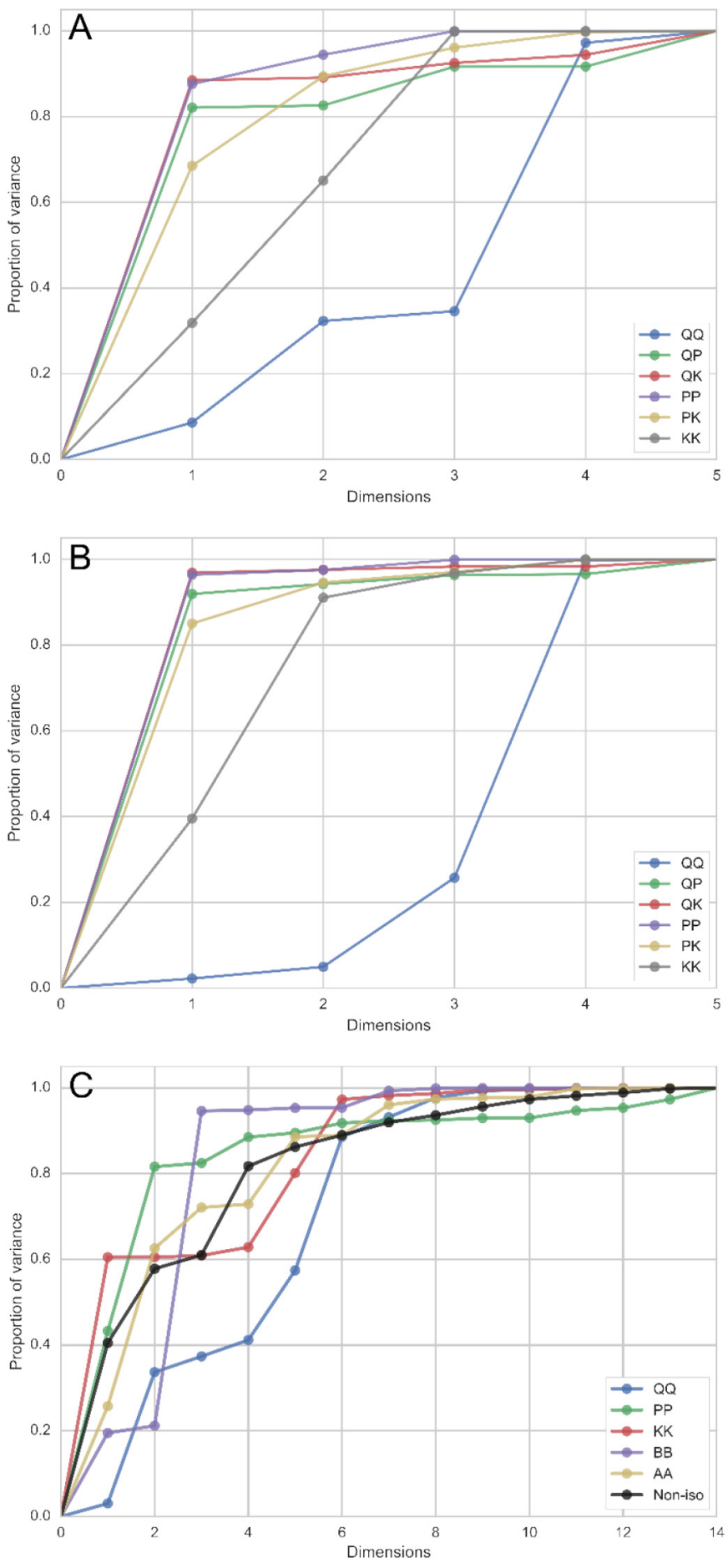

Fig. 9. Cumulative proportion of the variance reproduced for each interface type as a function of the number of dimensions in the model. A: QPK data of Meech Lake pluton (Vistelius et al., 1983); B: QPK data of nine plutons; C: QPKBA data from five plutons (Heins, 1992), with the average cumulative proportion of the variance reproduced for all non-isomineralic interfaces shown as a single category.

Hence, given the modal proportion of mineral $j\left(x_{j}\right)$, its crystal-size PDF $g(D)$, and a volume of rock to be simulated $(V)$, the total number of crystals of mineral $j$ in that volume $\left(n_{j}\right)$ can be calculated. With the help of the number frequencies so obtained we can recast the normalized relative frequencies of interfaces $\left(\alpha_{i}\right)$ into absolute frequencies $f_{i}$. The key to the statistical simplification that has been achieved in the above formulation is the role of the number-frequency distribution of crystals: it connects the PDFs of crystal size to the interface frequencies via the random texture model (which predicts relative interface frequencies based on relative number frequencies). The above approach will always produce an internally consistent quantitative joint description of rock texture and composition. No information is lost relative to conventional (intercorrelated) measures of texture, such as CSDs and interface densities, but there is much to be gained by adopting this approach.

The decoupling of texture and composition measures allows us to characterize the texture of granitoid rocks in terms of three statistically independent distributions (the modal composition $\mathbf{x}$, the probability density functions of crystal sizes $\mathbf{g}$, and the normalized interface frequencies $\alpha$ ). The added value of this approach relative to the conventional use of CSDs and interface densities is that it permits statistical testing of significant correlations among these distributions. Because the quantities into which we have partitioned texture and composition have been defined so as to be statistically independent, failure to reject the hypothesis of independence for real-world data sets by means of an appropriate multivariate statistical test implies that the data structure results from non-random petrogenetic processes. In the absence of large integrated data sets, we cannot tell whether or not relative interface-frequency distributions are in fact independent of crystalsize PDFs and/or modal composition, but the parameterisation we propose at least permits investigation of this null hypothesis, which we consider a major step forward. Because we are dealing with sets of multivariate data, the appropriate measures to extract for the purpose of statistical detection of petrogenetically significant patterns are the cross-covariance matrices (see Bloemsma et al., 2012, for an example of this approach).

Our approach to factorisation of the joint variability of rock texture and composition into statistically independent quantities follows in the footsteps of Griffiths (1961), who outlined the fundamentals of petrographic description by stating that a unique definition of a population as an assemblage of elements should be given in terms of fundamental properties. Most importantly, he stressed the fact that design requirements for measurement procedures aimed at operationally specifying these properties should permit the nature of the interrelationships among them to be objectively quantified. In the terminology of Griffiths (1961), the statistically independent quantities $\mathbf{x}, \mathbf{g}$, and $\alpha$ are fundamental properties, and intrinsically interdependent measures such as the CSD and interface density are derived properties, which result from some combination (interaction) of these.

The factorisation of texture and composition outlined above permits any combination of $\mathbf{x}, \mathbf{g}$, and $\alpha$ to be selected for the purpose of simulating a granitoid parent rock with internally consistent properties. Optional refinements to be accommodated within this framework are the shape and orientation distributions of crystals, which can also be formulated so as to be potentially independent of the other distributions. The next step would be to build an explicit 3-D model of a volume of granitoid rock which honours all of these constraints simultaneously (Harvey and Ferguson, 1978). Explicit geometric texture models have been recently proposed by several authors: Wang (2015), Van der Wielen and Rollinson (2016), and McCanta et al. (2017) discuss 2-D models, whereas 3-D models have been presented by Elsey et al. (2011), Miyoshi et al. (2017), and Hilden and Powell (2017). These models differ in the extent to which they accommodate crystal-size PDFs and non-random spatial distribution patterns of crystals. However, none of them permits a priori specification of interface-frequency patterns. We consider incorporation of interface-frequency constraints essential to modelling of sediment generation, because it will give us additional information on the topological characteristics of crystalline rocks, such as the PDFs of coordination numbers (the number of interfaces of each crystal), and the PDFs of interface areas (as opposed to the interface densities, which are averages), all of which are needed for a rigorous prediction of the composition of the mono- and polycrystalline grain populations generated from such rocks. 

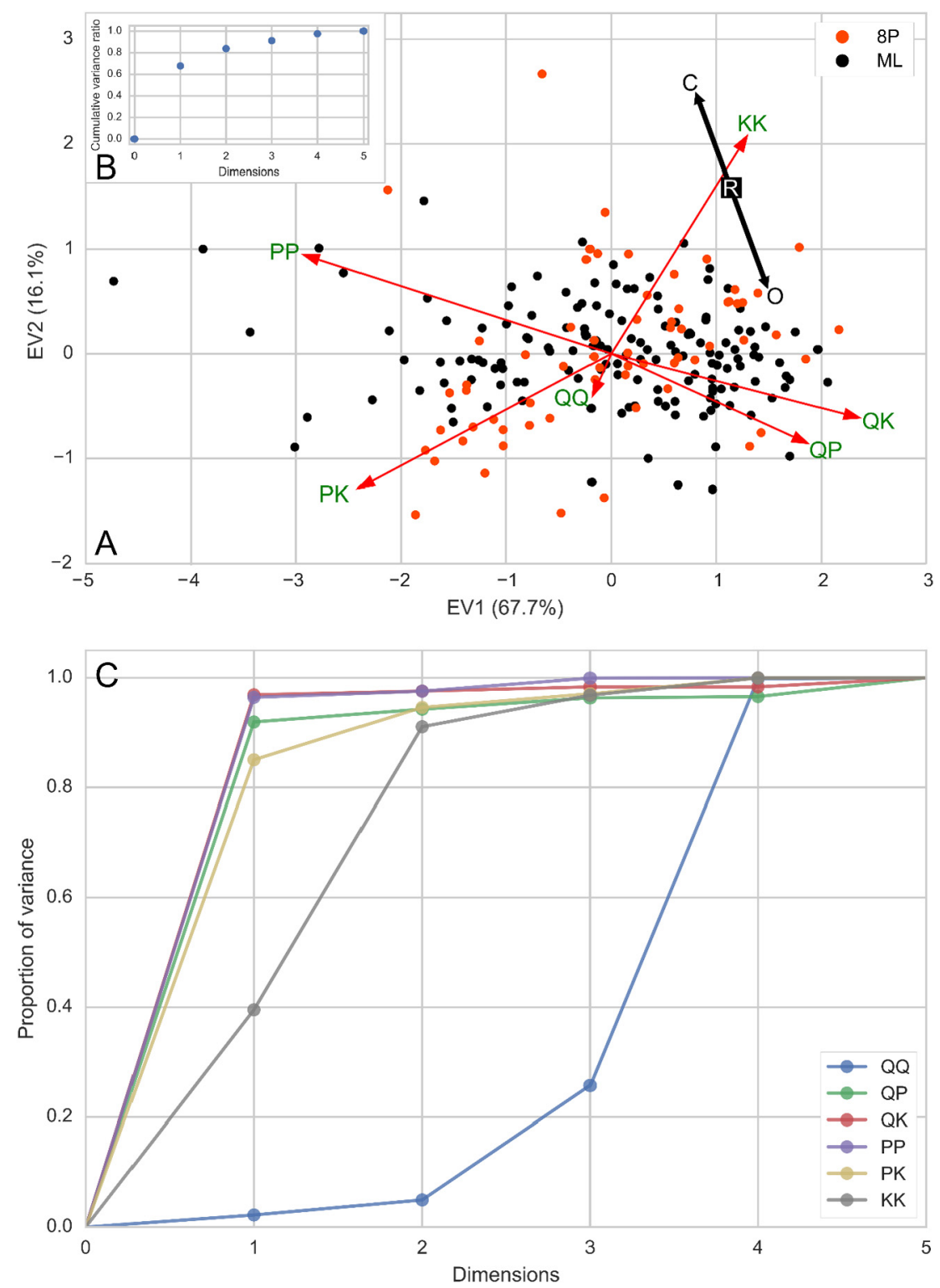

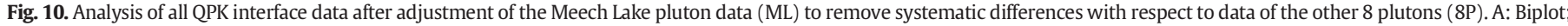

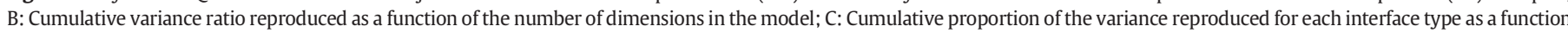
of the number of dimensions in the model.

\subsection{Application to sediment-generation studies}

As a result of our parameterisation of rock texture in terms of statistically independent quantities (the modal composition $\mathbf{x}$, the probability density functions of crystal sizes $\mathbf{g}$, and the normalized interface frequencies $\alpha$ ), we are now in a position to quantitatively describe the entire spectrum of granitoid parent rocks on the scale of thin sections. However, we still know very little about the spatial heterogeneity of petrographic properties of granitoid parent rocks on the scale of drainage basins in which sediments are generated. It is as yet unknown how interface-frequency data acquired in thin section can be extrapolated to the size of an entire drainage basin. The variability of modal composition and crystal-size distributions on the scale of an entire drainage basin are similarly unknown.

First-order monolithologic drainage basins, the smallest natural units in sediment-generation studies, typically offer a mixture of detritus generated in an area of several $\mathrm{km}^{2}$ to the fluvial system. If the spatial scale of maximum variability of granitoid texture and composition lies well below this scale, our estimates of average properties of granitoids will not materially improve by increasing the size of the data set or its spatial coverage. The fact that the variability within a single pluton (Vistelius et al., 1983) is about as large as the variability among eight other plutons suggests that this may be the case. On the other hand, it is not inconceivable that spatial trends in granitoid texture and composition in larger plutons will have to be taken into account for regional sediment-generation studies, i.e. those exceeding the size of first-order monolithologic drainage basins. The extent to which the variability of parent-rock texture and composition contributes to the variability of the generated sediment can only be addressed properly with more comprehensive data. At this stage, we cannot provide guidelines as to the number of specimens which should be analysed to provide a satisfactory description of the joint variability among crystal-size PDFs, relative interface frequencies, and modal composition. Development of automated 2-D and 3-D image analysis techniques that employ reliable criteria for identification of isomineralic interfaces (to give reproducible results) is needed to generate large data sets for systematic quantitative descriptions of crystalline rocks at the scale of entire batholiths and drainage basins. 


\section{Conclusions}

An objective quantitative description of parent-rock texture and composition is needed to specify the initial conditions for sediment generation. The time evolution of sediments, expressed in terms of the petrographic composition as a function of grain size, can only be understood if the compositional and textural variability of parent rocks has been properly characterized. This variability must be eliminated from petrographic data to permit robust estimation of relative strengths of crystal interfaces.

The crystal size distribution (CSD) as defined in petrology (Marsh, 1988; Higgins, 2000) is intrinsically coupled with the numberfrequency distribution of crystals. This dependency can be eliminated by converting the CSD to a probability density function of crystal size.

Patterns of crystal-interface frequencies which have been normalized to frequencies expected on the basis of random texture can be successfully summarized by a multivariate normal distribution in a reduced clr-space. The number of dimensions needed to describe the pattern may be taken equal to the number of mineral classes. The normalized crystal-interface frequencies are statistically independent of the number-frequency distribution of crystals in the rock, and of the probability density functions of their crystal sizes.

Analysis of 210 normalized QPK interface frequency distributions from nine different granitoids reveals a consistent pattern of variation among normalized interface frequencies, which suggests a single underlying petrogenetic process related to the combined effects of nucleation and textural equilibration ('coarsening').

Factorisation of textural and compositional variation into three statistically independent data sets (probability density functions of crystal size, normalized interface frequencies, and modal composition) follows the formal scheme outlined by Griffiths (1961) for the description of geological populations in terms of fundamental properties. This description opens the way to statistical testing of petrogenetic hypotheses which imply correlations among these data sets, and to computer simulation of the full spectrum of granitoids.

Large-scale patterns of compositional and textural variability within batholiths, which may reveal correlation among fundamental properties, have - to our knowledge - never been investigated. It is therefore difficult to place restrictions on the range of variability of the sediments supplied by such rock bodies to first-order drainage basins, the fundamental units of sediment generation.

Supplementary data to this article can be found online at https://doi. org/10.1016/j.sedgeo.2018.01.004.

\section{Acknowledgments}

With this paper we attempted to bring the work of Andrei Borisovich Vistelius to the attention of the petrological community. We wish to thank Sergey Kotov (MARUM, Bremen, Germany) for providing information on the fate of the Laboratory of Mathematical Geology (Saint Petersburg, Russia). Based on the publications of this defunct research institute, the size of the data base of QPK interface frequencies of samples from the many plutons analysed under the guidance of Vistelius over the course of three decades is estimated to be on the order of ten thousand. At this point, we do not know if this database still exists - and if it does, whether it will ever be made available to the scientific community. We thank Michael D. Higgins and Raimon Tolosana-Delgado for their perceptive reviews, which helped us to clarify the presentation of our results in the light of our objectives.

\section{Appendix 1. Operational definitions of interfaces in the data of Heins (1992)}

Standard thin sections were cut from all rock specimens, followed by aggressive etching with HF and staining with sodium cobaltinitrite.
Interfaces were counted along parallel linear transects using an optical microscope with transmitted light.

The recognition of isomineralic interfaces is discussed in Heins $(1992,1995)$. One could argue that it is impossible to define precisely the boundary between two crystals in an igneous rock: there is a continuum between sharp and gradual transitions, upon which we must arbitrarily impose an artificial distinction about what constitutes a real boundary. The original goal of Heins (1992) was to identify discontinuities within the rock that control disaggregation. He was therefore more likely to err on the side of accepting boundaries that might not be important, rather than missing ones that could be.

QQ interfaces: The chance of missing a QQ interface is exceedingly small. Boundaries between quartz crystals were inferred from discontinuities between regions of different extinction angle. Missing the boundary would require two adjacent crystals to crystalize with their optical axes close enough to parallel to lead to an extinction angle difference of $<5^{\circ}$, the probability of that in a granite is vanishingly small. Overestimation of the frequencies of QQ interfaces is a matter of greater concern. All of the samples have abundant instances where an individual crystal has diffuse domains of moderately different extinction, without sharp boundaries between the domains (see photos in Heins, 1992, 1995). There is a continuum between these diffuse boundaries and the sharp discontinuities that mark an unambiguous crystal-crystal contact. Possible errors could have originated from selecting a too-fuzzy transition as an actual contact.

It is, of course, possible that a different observation technique such as cathodoluminescence (CL) would reveal sharp boundaries that might be loci of disaggregation. There are certainly common planar concentrations of fluid inclusions to suggest that many quartz crystals contain healed fractures that would be visible in CL. However, despite the mechanical weakness imposed by the fluid inclusions themselves, healed fractures are not considered to represent zones of weakness or potential breakage. The fact that the fracture was healed with optically continuous quartz suggests that the repair was solid and durable.

PP interfaces: The plagioclase comes in two flavours; large crystals with composition $\sim \mathrm{An} 20-\mathrm{An} 40$, and pure albite reaction rims on $\mathrm{K}$-feldspar. The more calcic plagioclase is ubiquitously twinned, the albite is virtually twinless. The boundary between a twinned crystal and a rim is unmistakable. Misalignment of twin sets of $>10^{\circ}$ is readily apparent to even the untrained eye. Again, a possible concern is that PP boundaries between domains that properly belong to the "same" crystal have been counted as interfaces.

KK interfaces: Although the K-feldspar is not always twinned, it is easily recognizable due to the sodium cobaltinitrite stain. Heins (1992) used a very aggressive HF etch before staining, so that the crystallographic directions within individual crystals were highlighted. Once again, boundaries may have been counted when in fact there was just some minor variation of crystallographic axes within the 'same' crystal. Exsolution lamaelle within perthite crystals were also counted as KK contacts.

AA interfaces: this is the least well-defined category. There are some kinds of AA interfaces that are unambiguous: mostly inclusions of one accessory inside another, like apatite inside hornblende, or rutile inside biotite, for example, or less commonly a hornblende against a hornblende. Another kind of AA interface is between deuteric alteration products within the more calcic core of large, zoned plagioclases. In this case there is a kind of chaotic mishmash of sericite/muscovite, calcite, and opaques. Heins (1992) tried to count the AA, OA, and OO boundaries within this kind of zone as diligently and as consistently as possible, but it is likely that such data are sensitive to operator bias. Heins (1992) did not quantify the relative abundance of confident vs. unconfident AA boundaries, but the latter were probably more common.

OO interfaces: The volumetric abundance of opaques is low, and the interfaces between them are correspondingly rare. There could be interfaces within what Heins (1992) considered to be individual opaque 
crystals (e.g. titanite-illmenite intergrowths), but it was hardly relevant to the point of his original study. All interface data pertaining to opaque crystals have been left out at the insistence of both reviewers.

Non-isomineralic interfaces are in general less ambiguous, with the exception of:

QK interfaces: when a K-feldspar abuts a plagioclase, the K-feldspar often has an albite reaction rim against the plagioclase. Radiating out from the reaction rim into the K-feldspar are thin quartz myrmekite worms. These were counted as $\mathrm{QK}$ interfaces.

BA interfaces: If biotite is altered to chlorite, the sheets and books of the biotite are completely intact, even the extinction angle is preserved. The alteration is visible only as a colour change. These were also counted as BA interfaces, even though it might not actually be important for rock disaggregation.

\section{References}

Aitchison, J., 1986. The Statistical Analysis of Compositional Data. Chapman \& Hall, London (416 pp.).

Aitchison, J., Greenacre, M.J., 2002. Biplots of compositional data. Applied Statistics 51, 375-392.

Aleva, G.J.J., 1956a. Chemical and mechanical analysis of a tropically weathered granitic rock. Verhandelingen van het Koninklijk Nederlands Geologisch Mijnbouwkundig Genootschap, Geologische Serie 16, 1-11.

Aleva, G.J.J., 1956b. The grain size distribution of quartz in granitic rocks of Billiton, Indonesia. Geologie en Mijnbouw, New Series 18, 177-187.

Aleva, G.J.J., 1960. The plutonic igneous rocks from Billiton, Indonesia. Geologie en Mijnbouw 39, 427-436.

Blatt, H., 1967. Original characteristics of clastic quartz grains. Journal of Sedimentary Petrology 37, 401-424.

Bloemsma, M.R., Zabel, M. Stuut, J.B.W., Tjallingii, R. Collins, J.A., Weltje, G.J., 2012. Modelling the joint variability of grain size and chemical composition in sediments. Sedimentary Geology, 280, 135-148 + Corrigendum. Sedimentary Geology 284-285, 214 (2013).

Caracciolo, L., Tolosana-Delgado, R., Le Pera, E., von Eynatten, H., Arribas, J., Tarquini, S. 2012. Influence of granitoid textural parameters on sediment composition: implications for sediment generation. Sedimentary Geology 280, 93-107.

Davis, J.C., 2002. Statistics and Data Analysis in Geology. Wiley, Third edition (656 pp.).

Ehrlich, R., Vogel, T.A., Weinberg, B., Chapman Kamilli, D., Byerly, G., Richter, H., 1972. Textural variation in petrogenetic analyses. Geological Society of America Bulletin 83, 665-676.

Elsey, M., Esedoğlu, S., Smereka, P., 2011. Large-scale simulation of normal grain growth via diffusion-generated motion. Royal Society Proceedings, Mathematical, Physical and Engineering Sciences 467, 381-401.

Erkan, Y., 1970. Ein Versuch zur quantitative Erfassung der Festigkeitseigenschaften und zur quantitative Charakterisierung der Granite. Neues Jahrbuch für Mineralogie, Abhandlungen 113, 91-109.

Flinn, D., 1969. Grain contacts in crystalline rocks. Lithos 3, 361-370.

Griffiths, J.C., 1961. Measurement of the properties of sediments. Journal of Geology 69 487-498.

Harvey, P.K., Ferguson, C.C., 1978. A computer simulation approach to textural interpretation in crystalline rocks. In: Merriam, D.F. (Ed.), Recent Advances in Geomathematics: An International Symposium. Pergamon, pp. 201-232.

Heins, W.A., 1992. The Effect of Climate and Topography on the Composition of Modern Plutoniclastic Sand. University of California, Los Angeles (unpublished PhD thesis, 465 pp.).

Heins, W.A., 1993. Source rock texture versus climate and topography as controls on the composition of modern plutoniclastic sand. Geological Society of America, Special Paper 284, 135-146.

Heins, W.A., 1995. The use of mineral interfaces in sand-sized rock fragments to infer ancient climate. Geological Society of America Bulletin 107, 113-125.

Heins, W.A., Kairo, S., 2007. Predicting sand character with integrated genetic analysis Geological Society of America, Special Paper 420, 345-380.

Higgins, M.D., 2000. Measurement of crystal size distributions. American Mineralogist 85, $1105-1116$.

Higgins, M.D., 2002. Closure in crystal size distributions (CSD), verification of CSD calculations, and the significance of CSD fans. American Mineralogist 87, 171-175.

Higgins, M.D., 2006. Quantitative Textural Measurements in Igneous and Metamorphic Petrology. Cambridge University Press, Cambridge (270 pp.)

Higgins, M.D., 2011. Textural coarsening in igneous rocks. International Geology Review 53, 354-376.

Hilden, M.M., Powell, M.S., 2017. A geometrical texture model for multi-mineral liberation prediction. Minerals Engineering 111, 25-35.

Hoskin, C.M., Sundeen, D.A., 1985. Grain size of granite and derived grus, Enchanted Rock Pluton, Texas. Sedimentary Geology 42, 25-40.

Isaaks, E.H., Srivastava, R.M., 1989. An Introduction to Applied Geostatistics. Oxford University Press ( $561 \mathrm{pp}$.)

Jerram, D.A., Cheadle, M.J., Hunter, R.H., Elliott, M.T., 1996. The spatial distribution of grains and crystals in rocks. Contributions to Mineralogy and Petrology 125, 60-74.
Jerram, D.A., Cheadle, M.J., Philpotts, A.R., 2003. Quantifying the building blocks of igneous rocks: are clustered crystal frameworks the foundation? Journal of Petrology 44 2033-2051

Kretz, R., 1969. On the spatial distribution of crystals in rocks. Lithos 2, 39-65.

Le Bas, M.J., Streckeisen, A.L., 1991. The IUGS systematics of igneous rocks. Journal of the Geological Society, London 148, 825-833.

Lidstrom, L., 1968. Surface and bond-forming properties of quartz and silicate minerals and their application in mineral processing techniques. Acta Polytechnica Scandinavica, Chemistry Including Metallurgy Series 75 (149 pp.).

Mahan, S.M., Rogers, J.J.W., 1968. A study of grain contacts in some high grade metamorphic rocks. American Mineralogist 53, 323-327.

Marsh, B.D., 1988. Crystal size distribution (CSD) in rocks and the kinetics and dynamics of crystallization. Contributions to Mineralogy and Petrology 99, 277-291.

McCanta, M.C., Dyar, M.D., Dobosh, P.A., 2017. Extracting bulk rock properties from microscale measurements: subsampling and analytical guidelines. GSA Today 27. https:// doi.org/10.1130/GSATG290A.1.

McWilliams, R., 1966. The role of microstructure in the physical properties of rocks. In: The American Society for Testing Materials (Ed.), Testing Techniques for Rock Mechanics. A.S.T.M. Standards 402, pp. 175-189.

Miyoshi, E., Takaki, T., Ohno, M., Shibuta, Y., Sakane, S., Shimokawabe, T., Aoki, T., 2017 Ultra-large-scale phase-field simulation study of ideal grain growth. NPJ Computational Materials 3:25. https://doi.org/10.1038/s41524-017-0029-8.

Morishita, R., 1998. Statistical properties of ideal rock textures: relationship between crystal size distribution and spatial correlation of minerals. Mathematical Geology 30 409-434.

Morishita, R., Obata, M., 1995. A new statistical description of the spatial distribution of minerals in rocks. Journal of Geology 103, 232-240.

Moss, A.J., 1966. Origin, shaping and significance of quartz sand grains. Journal of the Geological Society of Australia 13, 97-136.

Moss, A.J., Green, P., 1975. Sand and silt grains: predetermination of their formation and properties by microfractures in quartz. Journal of the Geological Society of Australia 22, 485-495.

Pye, K., 1985. Granular disintegration of gneiss and migmatites. Catena 12, 191-199.

Pye, K., 1986. Mineralogical and textural controls on the weathering of granitoid rocks. Catena 13, 47-57.

Rogers, J.J.W., Bogy, D.B., 1958. A study of grain contacts in granitic rocks. Science 127 $470-471$.

Savanick, G.A., Johnson, D.I., 1974. Measurements of the strength of grain boundaries in rock. International Journal of Rock Mechanics and Mining Science and Geomechanics Abstracts 11, 173-180.

Sharp, W.E., Severance, K., 1991. Reversible Markov grain sequences in granite. Mathematical Geology 23, 305-324.

Simmons, G., Richter, D., 1976. Microcracks in Rocks. In: Strens, R.G.J. (Ed.), The Physics and Chemistry of Minerals and Rocks. Wiley, London, pp. 105-137.

Smalley, I.J., 1966. Formation of quartz sand. Nature 211, 476-479.

Tuttle, O.F., Bowen, N.L., 1958. Origin of granite in the light of experimental studies in the system $\mathrm{NaAlSi}_{3} \mathrm{O}_{8}-\mathrm{KalSi}_{3} \mathrm{O}_{8}-\mathrm{SiO}_{2}-\mathrm{H}_{2} \mathrm{O}$. Geological Society of America Memoirs 74 (146 pp.).

Van der Wielen, K.P., Rollinson, G., 2016. Texture-based analysis of liberation behaviour using Voronoi tessellations. Minerals Engineering 89, 93-107.

Van Tassell, J., Grant, W.H., 1980. Granite disintegration, Panola Mountain, Georgia. Journal of Geology 88, 360-364

Vistelius, A.B., 1972. Ideal granite and its properties. I: the stochastic model. Mathematical Geology 4, 89-102.

Vistelius, A.B., 1987. Ideal granites and models of their metasomatic transformations: theory, experience, and current problems. Mathematical Geology 19, 589-612.

Vistelius, A.B., Harbaugh, J.W., 1980. Granitic rocks of the Yosemite Valley and the ideal granite model. Mathematical Geology 12, 1-24.

Vistelius, A.B., Agterberg, F.P., Divi, S.R., Hogarth, D.D., 1983. A stochastic model for the crystallization and textural analysis of a fine-grained granite stock near Meech Lake, Gatineau Park. Canadian Geological Survey Paper 81-21 (62 pp.).

Vollbrecht, A., Rust, S., Weber, K., 1991. Development of microcracks in granites during cooling and uplift: examples from the Variscan basement in NE Bavaria, Germany. Journal of Structural Geology 13, 787-799.

Von Eynatten, H., 2004. Statistical modelling of compositional trends in sediments. Sedimentary Geology 171, 79-89.

Von Eynatten, H., Barceló-Vidal, C., Pawlowsky-Glahn, V., 2003. Modelling compositiona change: the example of chemical weathering of granitoid rocks. Mathematical Geology 35, 231-251.

Wang, Y., 2015. Numerical modelling of heterogeneous rock breakage behaviour based on texture images. Minerals Engineering 74, 130-141.

Weltje, G.J., 2012. Quantitative models of sediment generation and provenance: state of the art and future developments. Sedimentary Geology 280, 4-20.

White, S., 1976. The role of dislocation processes during tectonic deformations, with particular reference to quartz. In: Strens, R.G.J. (Ed.), The Physics and Chemistry of Minerals and Rocks. Wiley, London, pp. 75-91.

Whitten, E.H.T., Dacey, M.F., 1975. On the significance of certain Markovian features of granite textures. Journal of Petrology 16, 429-453.

Whitten, E.H.T., Dacey, M.F., Thompson, K.D., 1975. Markovian grain relationships of a Grenville granulite. American Journal of Science 275, 1164-1182. 